\title{
Efficacy and safety of airway stenting to treat anastomotic complications after lung transplant: a cohort study
}

\author{
Kevin C. Ma ${ }^{1}$, Mingyang $\mathrm{Li}^{2}$, Andrew R. Haas ${ }^{1}$, Anthony R. Lanfranco ${ }^{1}$, Edmund K. Moon ${ }^{1}$, \\ David M. DiBardino
}

${ }^{1}$ Section of Interventional Pulmonology, Division of Pulmonary, Allergy, \& Critical Care, ${ }^{2}$ Departments of Biostatistics, Epidemiology and Informatics, University of Pennsylvania, Philadelphia, PA, USA

Contributions: (I) Conception and design: KC Ma, DM DiBardino; (II) Administrative support: None; (III) Provision of study materials or patients: KC Ma, DM DiBardino; (IV) Collection and assembly of data: KC Ma, AR Haas, AR Lanfranco, EK Moon, DM DiBardino; (V) Data analysis and interpretation: KC Ma, M Li, DM DiBardino; (VI) Manuscript writing: All authors; (VII) Final approval of manuscript: All authors.

Correspondence to: Kevin C. Ma, MD. Assistant Professor of Clinical Medicine, Section of Interventional Pulmonology, Division of Pulmonary, Allergy and Critical Care, Perelman School of Medicine, University of Pennsylvania, 3400 Spruce Street, W. Gates Building - HUP, Philadelphia, PA 19104, USA. Email: kevin.ma@uphs.upenn.edu.

Background: Airway complications affect roughly 15-20\% of lung transplant patients. Airway stents are an attractive therapeutic option; however, no experimental or controlled observational data exists to draw firm conclusions regarding airway stent efficacy and safety in this population.

Methods: We performed a retrospective cohort study of patients who underwent airway stent placement for post-transplant anastomotic airway complications. The primary outcomes were improvements in FEV1 and reduction in bronchoscopies post-stent.

Results: We identified 36 patients who underwent airway stenting between October 2012 and October 2017. A total of 47 airways underwent stent placement. Improvement in FEV1 after stent placement was only observed in patients who ultimately were able to undergo stent removal. Patients who expired prior to stent removal had no immediate FEV1 improvement after stent placement. Among subjects who underwent stent removal, there was a statistically significant reduction in number of bronchoscopies per month after stent removal compared to pre-stent placement. Male gender was the only predictor of FEV1 improvement after stent placement while male gender and dehiscence prior to stent placement predicted increased number of bronchoscopies after stent placement. Mucous plugging and granulation tissue formation were the most common stent related complications.

Conclusions: Only select patients benefit from stent placement for airways stenosis after lung transplant. Complications related to stent placement are common. Patients with airway complications treated with airway stents undergo a high volume of repeat procedures.

Keywords: Lung transplantation; bronchoscopy; self expandable metallic stents

Submitted Jan 26, 2020. Accepted for publication Jun 11, 2020.

doi: $10.21037 /$ jtd-20-677

View this article at: http://dx.doi.org/10.21037/jtd-20-677

^ORCID: 0000-0002-0687-5401. 


\section{Introduction}

Airway complications after lung transplant continue to be a significant cause of morbidity post-transplant (1). Contemporary descriptive epidemiologic studies continue to report airway complications affecting roughly $15-20 \%$ of lung transplant patients $(2,3)$. Much of the work in this field has centered around identifying risk factors for airway complications. Many of the non-surgical associations identified are difficult to modify, such as primary graft dysfunction, acute cellular rejection, aspergillus colonization post-transplant, prolonged postoperative mechanical ventilation, single lung transplant, post-operative hypotension, and pre-operative Pseudomonas cepacia colonization (4-10).

Understanding the optimal treatment for these airway complications is critical. Research dedicated to therapeutic options has been limited by small subject numbers, a paucity of comparison arms, the historical lack of consensus definitions for the subtypes of airway complications, and institution-specific bias. These factors have led to a general lack of reproducibility and continued equipoise. Airway stents are an attractive option because airway complications often include airway stenoses that tend to recur after simple dilation techniques (7). Descriptive studies have demonstrated the feasibility of airway stents to treat certain airway complications (11-13). Improvement in FEV1 and improved respiratory symptoms after stent placement have been described $(12,13)$. However, no experimental or controlled observational data exists to draw firm conclusions regarding airway stents in this patient population (1).

In this retrospective cohort study, we report airway stent strategies and their associations with clinical outcomes in patients with post-transplant airway complications leading to airway stenosis. To our knowledge, this is the first observational study aimed at comparing airway stent techniques with clinical success. We present the following article in accordance with the STROBE reporting checklist (available at http://dx.doi.org/10.21037/jtd-20-677).

\section{Methods}

\section{Patient population}

This is a retrospective cohort study using patient data collected between October 2012 and October 2017. All consecutive post-lung transplant patients who had undergone airway stent placement for anastomotic airway complications during the study period were included in the database. Patients were excluded if airway stents were used to manage distal airways disease as previously defined in a 2018 International Society for Heart and Lung Transplantation (ISHLT) consensus statement (1).

Data was gathered by reviewing the electronic medical record and imported for analyses using SAS/Stat software, Version 9.4 (SAS Institute, Cary, North Carolina, USA). For all statistical tests, significance level alpha of 0.05 was used. Descriptive statistics for patient demographics were provided on both the patient and airway level as some patients had multiple airway complications requiring stenting, and reported using median and interquartile ranges for demographic, peri-operative, and donor-recipient variables.

\section{Statistical analysis}

\section{Primary endpoints}

One sample $t$-test was used to evaluate the hypotheses that airway stent placement was associated with a durable change in FEV1, and a change in the number of bronchoscopies required to maintain airway patency. Co-primary endpoints were measured as improvement in FEV1 in milliliters and decrease in monthly bronchoscopy rate measured before stent placement, immediately after stent placement, and, when available, after stent removal. Bronchoscopy was performed at the discretion of the treatment team including the patient's transplant pulmonologist as well as the interventional pulmonologist. Analyses were also repeated when stratified between airways with eventual stent removal, versus airways with permanent stent placement.

\section{Secondary endpoints}

Fisher's exact test was used to evaluate differences in stent related complications between different stent types. Simple and multiple linear regression were used to evaluate demographic and procedure factors associated with a change in FEV1 and monthly bronchoscopy rate.

Missing data points were omitted from the analysis. No patients were lost to follow up.

This research was conducted with University of Pennsylvania institutional review board approval (IRB \#828752). With the approval of the local IRB, informed consent was not obtained for the study due to its retrospective nature of the study. Subject data was kept secure in accordance with local IRB guidelines. The study conformed to the provisions of the Declaration of Helsinki (as revised in Edinburgh 2000). 


\section{Results}

Baseline characteristics by subject and by airway are shown in Table 1. We identified 36 subjects with airway stenting after lung transplant between October 2012 and October 2017. The mean age at transplant was 61 years old. The most common indication for transplant was idiopathic pulmonary fibrosis (IPF)/interstitial lung disease (ILD) $(\mathrm{n}=23,63.9 \%)$. Among the 36 subjects, a total of 47 airways underwent stent placement for a transplantrelated anastomotic complication with a median time from transplant to stent placement of 127 (IQR 82-201) days. The preferred initial stent choice was a silicone stent $(n=29,61.7 \%)$. Specific types of anastomotic complications were categorized as cicatrix (fibrotic scar tissue), pseudomembrane (sloughing formerly necrotic airway wall), dehiscence, or malacia.

\section{Changes in pulmonary function test parameters}

Among subjects who eventually had their stent removed, statistically significant improvements in FEV1 were observed immediately after placement $(0.41 \pm 0.39 \mathrm{~L}$, $\mathrm{P}<0.001)$ compared to pre-stent placement FEV1 (Table 2). Moreover, there was sustained FEV1 improvement immediately after stent removal as well as 1 year after removal. Among subjects who did not have their stent removed, no immediate improvement in FEV1 was observed after stent placement (Figure 1). There was a difference in location of stented airways between those subjects who eventually underwent stent removal compared to subjects who did not (Table 3). No other differences were noted in baseline characteristics between the two groups.

\section{Changes in the need for therapeutic bronchoscopy}

In addition, there was no statistically significant change in the number of bronchoscopies per month before and after stent placement (Table 4). Among subjects who underwent stent removal $(\mathrm{n}=28)$, there was a statistically significant reduction in number of bronchoscopies per month after stent removal compared to pre-stent placement.

\section{Stent related complications}

Stent-related complications were common (Table 5). The total median duration of stent placement was $258 \pm 308$ days. Mucous plugging $(\mathrm{n}=27,57.5 \%)$ and granulation tissue $(\mathrm{n}=17,36.2 \%)$ were the most common complications. When compared by type of stent placed, no differences were observed in complications.

\section{Predictors of improvements}

After multiple linear regression, male gender was the only predictor of FEV1 improvement after stent placement (Table S1). Male gender and increase number of bronchoscopies prior to stent placement predicted continued FEV1 improvement after stent removal (Table S2). Among patients with follow up 12 months after stent removal $(\mathrm{n}=15)$, an increased number of bronchoscopies before stent placement continued to predict a sustained FEV1 improvement. The time from identification of an anastomotic complication to stent placement was associated with a statistically significant, but clinically insignificant, improvement in FEV1 after stent placement (Table S3). Furthermore, after multiple linear regression, male gender and the presence of a dehiscence prior to stent placement predicted increased number of bronchoscopies per month after stent placement compared to pre-stent placement (Table S4). Among subjects who ultimately underwent stent removal with available data $(\mathrm{n}=21)$, increased number of stent exchanges was a predictor of decreased number of bronchoscopies after stent removal compared to pre-stent placement (Table S5). Stent exchanges were typically done at the discretion of the proceduralist due to complications related to the native stent such as mucous plugging, granulation tissue or stent migrations.

\section{Discussion}

In this retrospective cohort study, we describe associations between patient characteristics and improvement in FEV1 and need for additional bronchoscopic interventions. Complications related to stent placement are common but treatable with repeat bronchoscopy. Patients with airway complications treated with airway stents undergo a high volume of repeat procedures.

Subjects who underwent a successful period of stent placement and subsequent removal had statistically significant improvements in FEV1 both during the period of stent placement as well as sustained FEV1 improvements and decreased monthly bronchoscopies after stent removal. This data supports the notion that in a subset of stented patients airway remodeling can occur around the scaffolding of an airway stent. While the stented period often requires 
Table 1 Baseline demographics

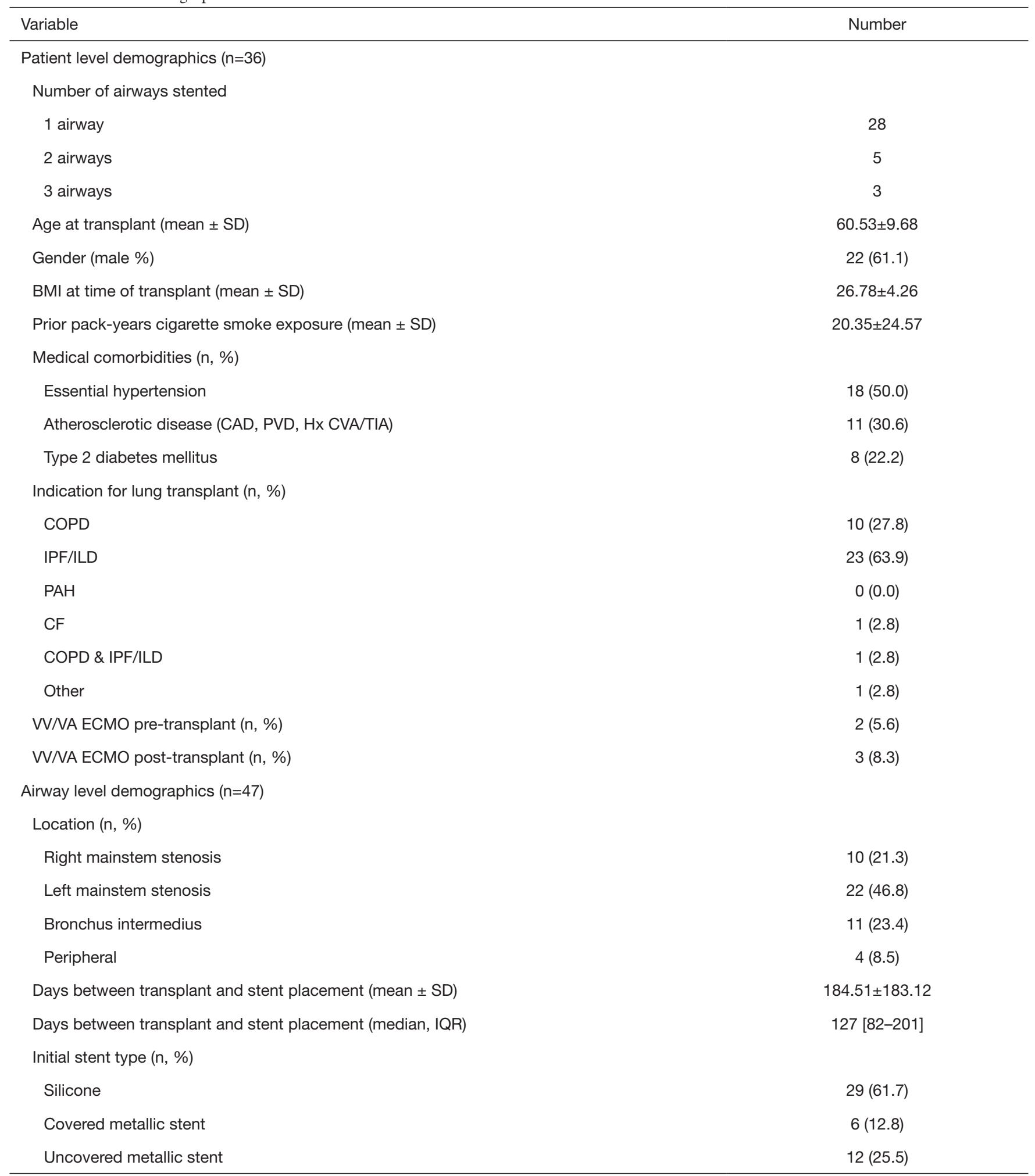

Table 1 (Continued) 
Table 1 (Continued)

\begin{tabular}{lc}
\hline Variable & Number \\
\hline Dehiscence $(\mathrm{n}, \%)$ & $6(12.8)$ \\
Cicatrix $(\mathrm{n}, \%)$ & $19(40.4)$ \\
Pseudomembrane $(\mathrm{n}$, \%) & $14(29.8)$ \\
Malacia $(\mathrm{n}, \%)$ & $19(40.4)$ \\
FEV1 (L) & $1.44 \pm 0.57$ \\
Procedures prior to stent placement (mean \pm SD) & $0.83 \pm 1.19$ \\
\# of dilations & $1.28 \pm 2.67$ \\
\# of debridements & $0.38 \pm 0.99$ \\
\# of aspirations for mucous plugging & $0.11 \pm 0.31$ \\
\# of steroid injections & $0.26 \pm 0.79$ \\
\# of cryotherapy treatments & $4.62 \pm 3.38$ \\
\# of Bronchoscopies & \\
\hline
\end{tabular}

BMI, body mass index; CAD, coronary artery disease; PVD, peripheral vascular disease; CVA/TIA, cerebral vascular attacks/transient ischemic attacks; COPD, chronic obstructive pulmonary disease; IPF/ILD, idiopathic pulmonary fibrosis/interstitial lung disease; PAH, pulmonary arterial hypertension; CF, cystic fibrosis; VV/VA, veno-venous/veno-arterial; ECMO, extra-corporeal membrane oxygenation; FEV1, forced expiratory volume in one second.

Table 2 Improvement in FEV1 after stent placement and removal

\begin{tabular}{|c|c|c|c|c|c|c|c|c|c|c|c|c|}
\hline Variable & \multicolumn{4}{|c|}{ Stent removed } & \multicolumn{4}{|c|}{ Stent never removed } & \multicolumn{4}{|c|}{ All } \\
\hline $\begin{array}{l}\text { Stent placement (post-stent } \\
\text { FEV1 - pre-FEV1) }\end{array}$ & 21 & 0.41 & 0.39 & $<0.001$ & 13 & 0.25 & 0.59 & 0.3278 & 34 & 0.35 & 0.47 & $<0.001$ \\
\hline $\begin{array}{l}\text { Stent removal, short term } \\
\text { (stent removal FEV1 - pre-FEV1) }\end{array}$ & 22 & 0.35 & 0.37 & $<0.001$ & $\mathrm{~N} / \mathrm{A}$ & $\mathrm{N} / \mathrm{A}$ & N/A & $\mathrm{N} / \mathrm{A}$ & $\mathrm{N} / \mathrm{A}$ & $\mathrm{N} / \mathrm{A}$ & N/A & $\mathrm{N} / \mathrm{A}$ \\
\hline
\end{tabular}

${ }^{1}, t$-test: H0: delta $=0 ;{ }^{2}, \mathrm{P}$ value comparing (post-stent FEV1 - pre-FEV1) between patients who had stent removed vs. not removed. FEV1, forced expiratory volume in one second.

repeat bronchoscopy to manage complications, there is the potential decrease in airway interventions after stent removal. These benefits were not seen in patients with indefinite airway stenting. We noted that patients who could not have their stent removed were more likely to have LMSB or RBI disease. It seems plausible that patients that could not have their stent removed were likely to have more complex airway stenosis that was more difficult to treat endoscopically without full relief of their obstruction after airway stent placement. Furthermore, they may have been sicker individuals with confounding reasons leading to low FEV1, more bronchoscopy, and a perception that stent removal had prohibitive risk.

In our multivariate analysis of possible predictors of stent success, only a few factors came to light. Male gender was shown to be a predictor of immediate improvement in FEV1 after stent placement and sustained improvement after stent removal. We conjecture that perhaps a larger thoracic cavity allows for more apparent improvements in FEV1 after relief of stenosis. Furthermore, larger native 


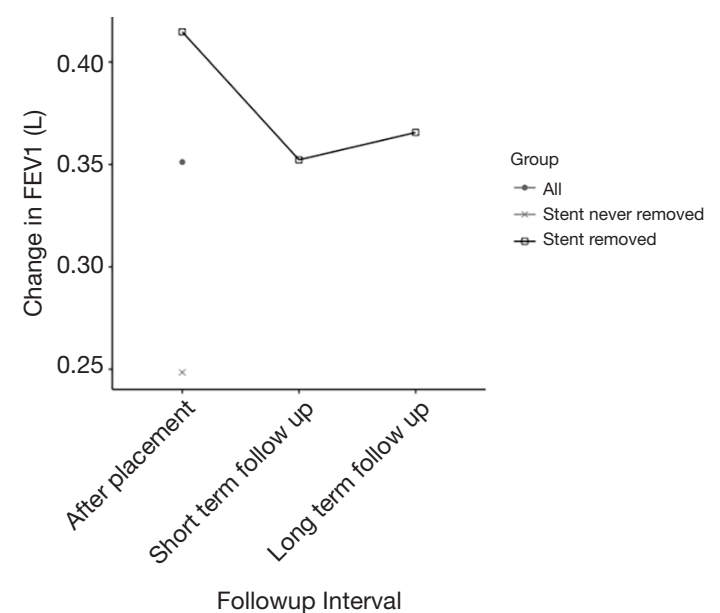

Figure 1 Change in FEV1 over time. FEV1, forced expiratory volume in one second. Short-term follow up, short-term follow up after stent removal. Long-term follow up, 1 year follow up after stent removal. airway size allows for easier and more effective stenting across a stenosis. Paradoxically, male gender was also a predictor of increased need for bronchoscopy after stent placement though from the data available no inferences could be made as to the reason. Furthermore, airway dehiscence prior to stenting was a predictor of need for post-stent placement bronchoscopy. It is very possible that the major factor related to successful airway stenting is the endoscopic phenotype and anatomy of the airway complication itself. The exact anatomy and airway biology is probably an important determinant of stent related granulation tissue and mucous plugging, both of which lead to more bronchoscopies and a lower FEV1.

Regardless of the success of airway stenting, frequent bronchoscopy appears to be a major feature of this patient population. While this has been observed and indirectly described in the literature previously, this is an important

Table 3 Comparative differences between patients who underwent stent removal vs. patients who did not undergo stent removal

\begin{tabular}{|c|c|c|c|}
\hline Variable & Stent removed & Stent never removed & $P$ value \\
\hline \multicolumn{4}{|l|}{ Patient level demographics $(n=36)$} \\
\hline Number of airways stented & & & $N S^{2}$ \\
\hline 1 airway & 18 & 10 & \\
\hline 2 airways & 1 & 4 & \\
\hline 3 airways & 3 & 0 & \\
\hline Age at transplant (mean $\pm \mathrm{SD})$ & $61.28 \pm 9.69$ & $59.35 \pm 9.91$ & $\mathrm{NS}^{3}$ \\
\hline Gender (male \%) & $12(54.5)$ & $10(71.4)$ & $\mathrm{NS}^{1}$ \\
\hline $\mathrm{BMI}$ at time of transplant (mean $\pm \mathrm{SD}$ ) & $25.82 \pm 4.86$ & $28.29 \pm 2.58$ & $\mathrm{NS}^{3}$ \\
\hline Prior pack years cigarette smoke exposure (mean \pm SD) & $25.45 \pm 28.70$ & $12.32 \pm 13.47$ & $\mathrm{NS}^{3}$ \\
\hline \multicolumn{4}{|l|}{ Medical comorbidities (n, \%) } \\
\hline Essential hypertension & $11(50.0)$ & $7(50.0)$ & $N S^{1}$ \\
\hline Atherosclerotic disease CAD/PVD/stroke & $7(31.8)$ & $4(28.6)$ & $N S^{2}$ \\
\hline Type 2 diabetes mellitus & $4(18.2)$ & $4(28.6)$ & $N S^{2}$ \\
\hline Indication for lung transplant (n, \%) & & & $N S^{2}$ \\
\hline COPD & $8(36.4)$ & $2(14.3)$ & \\
\hline IPF/ILD & $12(54.5)$ & $11(78.6)$ & \\
\hline PAH & $0(0.0)$ & $0(0.0)$ & \\
\hline $\mathrm{CF}$ & $1(4.5)$ & $0(0.0)$ & \\
\hline COPD \& ILDIPF & $1(4.5)$ & $0(0.0)$ & \\
\hline Other & $0(0.0)$ & $1(7.1)$ & \\
\hline
\end{tabular}

Table 3 (Continued) 
Table 3 (Continued)

\begin{tabular}{|c|c|c|c|}
\hline Variable & Stent removed & Stent never removed & $P$ value \\
\hline VV/VA ECMO post-transplant (n, \%) & $1(4.5)$ & $2(14.3)$ & $\mathrm{NS}^{2}$ \\
\hline \multicolumn{4}{|l|}{ Airway level demographics $(n=47)$} \\
\hline Location (n, \%) & & & $0.03^{2}$ \\
\hline Left mainstem stenosis & $11(37.9)$ & $11(61.1)$ & \\
\hline Bronchus intermedius & $5(17.2)$ & $6(33.3)$ & \\
\hline Peripheral & $4(13.8)$ & $0(0.0)$ & \\
\hline Days between transplant and stent placement (mean \pm SD) & $154.07 \pm 152.06$ & $233.56 \pm 220.29$ & $\mathrm{NS}^{3}$ \\
\hline Silicone & $17(58.6)$ & $12(66.7)$ & \\
\hline Covered metallic stent & $4(13.8)$ & $2(11.1)$ & \\
\hline Uncovered metallic stent & $8(27.6)$ & $4(22.2)$ & \\
\hline Dehiscence (n, \%) & $5(17.2)$ & $1(5.6)$ & $\mathrm{NS}^{2}$ \\
\hline Cicatrix (n, \%) & $10(34.5)$ & $9(50.0)$ & $\mathrm{NS}^{1}$ \\
\hline Pseudomembrane (n, \%) & $9(31.0)$ & $5(27.8)$ & $\mathrm{NS}^{1}$ \\
\hline Malacia (n, \%) & $10(34.5)$ & $9(50.0)$ & $\mathrm{NS}^{1}$ \\
\hline FEV1 (L) (mean \pm SD) & $1.40 \pm 0.60$ & $1.50 \pm 0.54$ & $\mathrm{NS}^{3}$ \\
\hline \# of cryotherapy treatments & $0.34 \pm 0.97$ & $0.11 \pm 0.32$ & $\mathrm{NS}^{3}$ \\
\hline \# of Bronchoscopies & $4.55 \pm 3.62$ & $4.72 \pm 3.04$ & $\mathrm{NS}^{3}$ \\
\hline
\end{tabular}

${ }^{1}$, Chi-square test; ${ }^{2}$, Fisher's exact test; ${ }^{3}$, two-sample $t$-test. NS, not significant. $\%=\mathrm{n} / \mathrm{N}$, where $\mathrm{N}$ is total counts on subject/airway level. Total counts on subject level: stent removed 22; stent never removed 14; all 36. Total counts on airway level: stent removed 29; stent never removed 18; all 47. BMI, body mass index; CAD, coronary artery disease; PVD, peripheral vascular disease; COPD, chronic obstructive pulmonary disease; IPF/ILD, idiopathic pulmonary fibrosis/interstitial lung disease; PAH, pulmonary arterial hypertension; CF, cystic fibrosis; VV/VA, veno-venous/veno-arterial; ECMO, extra-corporeal membrane oxygenation; FEV1, forced expiratory volume in one second.

conclusion of the study. This observation can be used to appropriately set expectations for patients and transplant programs at the time an airway complication is diagnosed. Airway stenting may eventually decrease the need for bronchoscopy after stent removal in FEV1-responsive patients but seems unlikely to reduce that need before airway remodeling has occurred.

Airway stenting was generally safe and well tolerated. All stent deployment procedures occurred without complications; however, the obvious downside is the need 
Table 4 Change in monthly rate of bronchoscopies after stent placement and after stent removal

\begin{tabular}{|c|c|c|c|c|c|c|c|c|}
\hline Variable & \multicolumn{4}{|c|}{ Patients who had stent removed } & \multicolumn{4}{|c|}{ Patients who did not have stent removed } \\
\hline $\begin{array}{l}\text { Stent placement (during-stent bronch/ } \\
\text { month - pre-stent bronch/month) }\end{array}$ & 29 & -0.07 & 1.25 & 0.7544 & 18 & -0.19 & 0.4 & 0.635 \\
\hline $\begin{array}{l}\text { Stent removal (after stent removal bronch/ } \\
\text { month - pre-stent bronch/month) }\end{array}$ & 28 & -0.61 & 0.73 & $<0.001$ & $N / A$ & N/A & $\mathrm{N} / \mathrm{A}$ & N/A \\
\hline
\end{tabular}

${ }^{1}$, $t$-test: HO: delta $=0 ;{ }^{2}, \mathrm{P}$ value comparing (during-stent bronch/month - pre-stent bronch/month) between patients who had stent removed vs. not removed. bronch, bronchoscopy.

Table 5 Stent related complications

\begin{tabular}{lcccc}
\hline Variable & All stents $(\mathrm{n}=47)$ & Silicone stent $(\mathrm{n}=29)$ & $\begin{array}{c}\text { Covered metal stent } \\
(\mathrm{n}=6)\end{array}$ & UCMS (n=12) \\
\hline Any unplanned stent exchange & & & & \\
Total stent exchanges, N (SD) & $1.06 \pm 1.98$ & $0.55 \pm 1.12$ & $1.33 \pm 3.27$ & $2.17 \pm 2.52$ \\
Stent migration (n, \%) & $14(29.8)$ & $9(31.0)$ & $1(16.7)$ & $4(33.3)$ \\
Granulation tissue (n, \%) & $17(36.2)$ & $11(37.9)$ & $2(33.3)$ & $4(33.3)$ \\
Mucous plugging (n, \%) & $27(57.5)$ & $18(62.1)$ & $4(66.7)$ & $5(41.7)$ \\
Bleeding (n, \%) & $4(8.5)$ & $3(10.3)$ & $0(0)$ & 1.000 \\
Fracture (n, \%) & $0(0)$ & $0(0)$ & $0(0)$ & 0.566 \\
Restenosis (n, \%) & $9(19.2)$ & $5(17.24)$ & $3(50.0)$ & 1.000 \\
Dehiscence (n, \%) & $2(4.3)$ & $0(0)$ & $0(0)$ & $1(8.3)$ \\
Stent days (mean SD) & $321.26 \pm 359.18$ & $371.79 \pm 413.79$ & $130.00 \pm 85.20$ & $2(16.67)$ \\
Stent days (median, IQR) & $258[308]$ & $296[317]$ & $108[107]$ & 0.150 \\
\hline
\end{tabular}

for frequent bronchoscopy for stent maintenance. Based on the 2007 FDA black box warning against self-expanding metal stent placement in benign disease, our practice has been to preferentially place silicone stents in this patient population. At the time of the FDA black box warning, no fully covered SEMS were commercially available. With several fully covered SEMS now available, choosing a stent that conforms to the unique anatomic constraints of the airway stenosis may be more important than the stent material. Interestingly, the risk of stent-related complications did not vary based on stent type deployed. Mucous plugging could be most closely tied to patient related factors such as intrinsic microbiome (14).

Our study has several limitations. Firstly, this is a retrospective cohort analysis and therefore did not allow a priori gathering of defined exposures or outcomes of relevance. It would have been ideal to identify a clinically- meaningful outcome measure (e.g., airway luminal diameter, validated dyspnea scales, and/or patient quality of life) that could be recorded prospectively rather than spirometry values alone. FEV1 is an easy variable to use retrospectively since it is measured frequently in post-lung transplant patients and is considered an accurate measurement of airway obstruction. However, it does change due to several confounding disease processes such as acute or chronic rejection, infection, and fibrotic allograft changes. We utilized frequency of bronchoscopies as a more patientcentered outcome as frequent procedural intervention can become physically and mentally burdensome for patients. Secondly, no formalized protocol was utilized and thus decisions regarding timing and type of stent placement was left at the discretion of the bronchoscopist. Furthermore, this cohort included only those patients who had airway stenting performed. Many important questions regarding 
the utility of stenting compared to balloon dilation, submucosal steroid injection, debridement, and other less commonly used techniques remain unaddressed in this study. Future directions include cohort studies that include all patients with airway complications after lung transplant and can measure patient-centered outcomes as they vary between bronchoscopic treatment strategies. Such studies could also work to phenotype airway complications (dehiscence, stenosis, distal airway versus anastomosis, etc.) and describe differences in the natural evolution of these various phenotypes. Taking our airway stent data as a proof of concept, one could envision an experimental study comparing an airway stenting versus non-stenting strategy.

In conclusion, our study shows that airway stenting can be an effective and durable solution in select post-transplant airway stenoses. However, patient selection remains critical and specific patient factors that predict success remain elusive.

\section{Acknowledgments}

Funding: None.

\section{Footnote}

Reporting Checklist: The authors have completed the STROBE reporting checklist. Available at http://dx.doi. org/10.21037/jtd-20-677

Data Sharing Statement: Available at http://dx.doi. org/10.21037/jtd-20-677

Conflicts of Interest: All authors have completed the ICMJE uniform disclosure form (available at http://dx.doi. org/10.21037/jtd-20-677). ARH reports personal fees and other from Olympus America, Inc., outside the submitted work; DMD reports personal fees from Boston Scientific, outside the submitted work. The other authors have no conflicts of interest to declare.

Ethical Statement: The authors are accountable for all aspects of the work in ensuring that questions related to the accuracy or integrity of any part of the work are appropriately investigated and resolved. This research was conducted with University of Pennsylvania institutional review board approval (IRB \#828752). With the approval of the local IRB, informed consent was not obtained for the study due to its retrospective nature of the study.
Subject data was kept secure in accordance with local IRB guidelines. The study conformed to the provisions of the Declaration of Helsinki (as revised in 2013).

Open Access Statement: This is an Open Access article distributed in accordance with the Creative Commons Attribution-NonCommercial-NoDerivs 4.0 International License (CC BY-NC-ND 4.0), which permits the noncommercial replication and distribution of the article with the strict proviso that no changes or edits are made and the original work is properly cited (including links to both the formal publication through the relevant DOI and the license). See: https://creativecommons.org/licenses/by-nc-nd/4.0/.

\section{References}

1. Crespo MM, McCarthy DP, Hopkins PM, et al. ISHLT Consensus Statement on adult and pediatric airway complications after lung transplantation: Definitions, grading system, and therapeutics. J Heart Lung Transplant 2018;37:548-63.

2. Yserbyt J, Dooms C, Vos R, et al. Anastomotic airway complications after lung transplantation: risk factors, treatment modalities and outcome-a single-centre experience. Eur J Cardiothorac Surg 2016;49:e1-e8.

3. Murthy SC, Blackstone EH, Gildea TR, et al. Impact of anastomotic airway complications after lung transplantation. Ann Thorac Surg 2007;84:401-9, 409.e1-4.

4. Ruttmann E, Ulmer H, Marchese M, et al. Evaluation of factors damaging the bronchial wall in lung transplantation. J Heart Lung Transplant. 2005;24:275-81.

5. Castleberry AW, Worni M, Kuchibhatla M, et al. A comparative analysis of bronchial stricture after lung transplantation in recipients with and without early acute rejection. Ann Thorac Surg 2013;96:1008-17; discussion 1017-8.

6. Alvarez A, Algar J, Santos F, et al. Airway complications after lung transplantation: a review of 151 anastomoses. Eur J Cardiothorac Surg 2001;19:381-7.

7. Chhajed PN, Malouf MA, Tamm M, et al. Interventional bronchoscopy for the management of airway complications following lung transplantation. Chest 2001;120:1894-9.

8. Herrera JM, McNeil KD, Higgins RS, et al. Airway complications after lung transplantation: treatment and long-term outcome. Ann Thorac Surg 2001;71:989-93; discussion 993-4.

9. Choong CK, Sweet SC, Zoole JB, et al. Bronchial airway anastomotic complications after pediatric lung 
transplantation: incidence, cause, management, and outcome. J Thorac Cardiovasc Surg 2006;131:198-203.

10. Patterson GA, Todd TR, Cooper JD, et al. Airway complications after double lung transplantation. Toronto Lung Transplant Group. J Thorac Cardiovasc Surg 1990;99:14-20; discussion 20-1.

11. Mughal MM, Gildea TR, Murthy S, et al. Short-term deployment of self-expanding metallic stents facilitates healing of bronchial dehiscence. Am J Respir Crit Care Med 2005;172:768-71.

12. Gottlieb J, Fuehner T, Dierich M, et al. Are metallic

Cite this article as: $\mathrm{Ma} \mathrm{KC}, \mathrm{Li} \mathrm{M}$, Haas AR, Lanfranco AR, Moon EK, DiBardino DM. Efficacy and safety of airway stenting to treat anastomotic complications after lung transplant: a cohort study. J Thorac Dis 2020;12(7):3539-3548. doi: $10.21037 /$ jtd-20-677 stents really safe? A long-term analysis in lung transplant recipients. Eur Respir J 2009;34:1417-22.

13. Sundset A, Lund MB, Hansen G, et al. Airway complications after lung transplantation: long-term outcome of silicone stenting. Respiration 2012;83:245-52.

14. McGinniss JE, Imai I, Simon-Soro A, et al. Molecular analysis of the endobronchial stent microbial biofilm reveals bacterial communities that associate with stent material and frequent fungal constituents. PLoS One 2019;14:e0217306. 
Supplementary

Table S1 Predictors of FEV1 improvement after stent placement. Y = $\Delta$ FEV1 (post-stent - pre), $n=31$

\begin{tabular}{|c|c|c|c|c|c|c|c|c|c|c|c|c|}
\hline \multirow[b]{2}{*}{ Predictors } & \multicolumn{4}{|c|}{ Univariate } & \multicolumn{4}{|c|}{ Multivariate } & \multicolumn{4}{|c|}{ Reduced } \\
\hline & Estimate & $\begin{array}{l}\text { Standard } \\
\text { error }\end{array}$ & $t$-value & $P$ value & Estimate & $\begin{array}{l}\text { Standard } \\
\text { error }\end{array}$ & $t$-value & $\mathrm{P}$ value & Estimate & $\begin{array}{l}\text { Standard } \\
\text { error }\end{array}$ & $t$-value & $\mathrm{P}$ value \\
\hline Age at transplant & 0.01 & 0.01 & 1.85 & 0.075 & 0.01 & 0.01 & 1.35 & 0.189 & - & - & - & - \\
\hline Gender & 0.54 & 0.14 & 3.86 & 0.001 & 0.43 & 0.16 & 2.7 & 0.012 & 0.54 & 0.14 & 3.86 & 0.001 \\
\hline Baseline FEV1 & 0.01 & 0.15 & 0.05 & 0.961 & - & - & - & - & - & - & - & - \\
\hline Location of stent & & & & 0.352 & & & & & & & & \\
\hline LMSB & -0.14 & 0.25 & -0.56 & 0.577 & - & - & - & - & - & - & - & - \\
\hline RMSB & -0.48 & 0.29 & -1.64 & 0.112 & - & - & - & - & - & - & - & - \\
\hline $\mathrm{RBI}$ & -0.26 & 0.3 & -0.86 & 0.398 & - & - & - & - & - & - & - & - \\
\hline Peripheral & REF & & & & & & & & & & & \\
\hline Type of stent & & & & 0.118 & & & & 0.864 & & & & \\
\hline CSEMS & -0.07 & 0.27 & -0.27 & 0.786 & 0.09 & 0.26 & 0.35 & 0.729 & - & - & - & - \\
\hline USEMS & -0.46 & 0.22 & -2.15 & 0.04 & -0.08 & 0.27 & -0.28 & 0.78 & - & - & - & - \\
\hline Silicone & REF & & & & REF & & & & & & & \\
\hline \multicolumn{13}{|l|}{ Type of airway complication } \\
\hline Dehiscence & -0.33 & 0.28 & -1.19 & 0.245 & & & & & & - & - & - \\
\hline Cicatrix Scar & 0.19 & 0.16 & 1.13 & 0.268 & - & - & - & - & - & - & - & - \\
\hline Pseudomembrane & -0.49 & 0.19 & -2.54 & 0.017 & -0.15 & 0.26 & -0.57 & 0.575 & - & - & - & - \\
\hline Malacia & -0.01 & 0.17 & -0.05 & 0.959 & - & - & - & - & - & - & - & - \\
\hline $\begin{array}{l}\text { \# of bronchoscopies/month } \\
\text { pre stent }\end{array}$ & -0.08 & 0.15 & -0.52 & 0.61 & - & - & - & - & - & - & - & - \\
\hline Days prior to stent placement & 0 & 0 & 0.62 & 0.54 & - & - & - & - & - & - & - & - \\
\hline
\end{tabular}

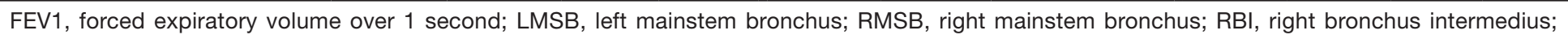
CSEMS, covered self expanding metallic stent; USEMS, uncovered self expanding metallic stent. 
Table S2 Predictors of FEV1 improvement immediately after stent removal. $\mathrm{Y}=\Delta \mathrm{FEV} 1$ (stent removal - pre), $\mathrm{n}=19$

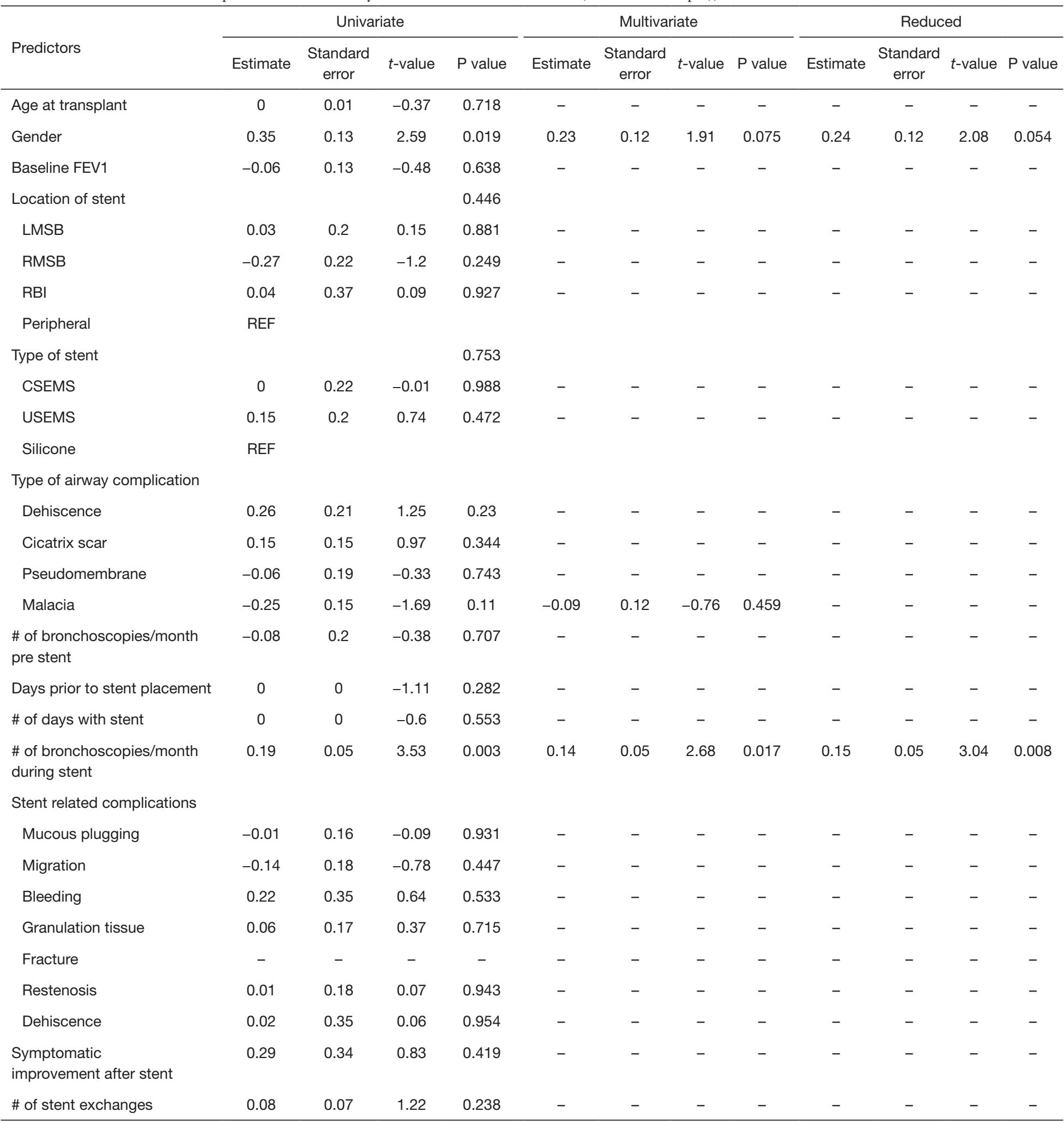

FEV1, forced expiratory volume over 1 second; LMSB, left mainstem bronchus; RMSB, right mainstem bronchus; RBI, right bronchus intermedius; CSEMS, covered self expanding metallic stent; USEMS, uncovered self expanding metallic stent. 
Table S3 Predictors of sustained FEV1 improvement 12 months after stent removal. Y= $\Delta$ FEV1(12-month stent removal - pre), $\mathrm{n}=15$

\begin{tabular}{|c|c|c|c|c|c|c|c|c|c|c|c|c|}
\hline \multirow[b]{2}{*}{ Predictors } & \multicolumn{4}{|c|}{ Univariate } & \multicolumn{4}{|c|}{ Multivariate } & \multicolumn{4}{|c|}{ Reduced } \\
\hline & Estimate & $\begin{array}{l}\text { Standard } \\
\text { error }\end{array}$ & $t$-value & $P$ value & Estimate & $\begin{array}{l}\text { Standard } \\
\text { error }\end{array}$ & $t$-value & $P$ value & Estimate & $\begin{array}{c}\text { Standard } \\
\text { error }\end{array}$ & $t$-value & $P$ value \\
\hline Age at transplant & -0.01 & 0.01 & -0.66 & 0.521 & - & - & - & - & - & - & - & - \\
\hline Gender & 0.26 & 0.25 & 1.02 & 0.328 & - & - & - & - & - & - & - & - \\
\hline Baseline FEV1 & -0.15 & 0.2 & -0.76 & 0.463 & - & - & - & - & - & - & - & - \\
\hline Location of stent & & & & 0.742 & & & & & & & & \\
\hline LMSB & -0.11 & 0.35 & -0.31 & 0.759 & - & - & - & - & - & - & - & - \\
\hline RMSB & -0.39 & 0.39 & -1 & 0.341 & - & - & - & - & - & - & - & - \\
\hline RBI & -0.34 & 0.59 & -0.57 & 0.58 & - & - & - & - & - & - & - & - \\
\hline Peripheral & REF & & & & & & & & & & & \\
\hline Type of stent & & & & 0.096 & & & & 0.844 & & & & \\
\hline CSEMS & 0.25 & 0.33 & 0.77 & 0.458 & 0.12 & 0.24 & 0.5 & 0.634 & - & - & - & - \\
\hline USEMS & 0.66 & 0.28 & 2.37 & 0.035 & 0.12 & 0.25 & 0.46 & 0.655 & - & - & - & - \\
\hline Silicone & REF & & & & REF & & & & & & & \\
\hline \multicolumn{13}{|l|}{ Type of airway complication } \\
\hline Dehiscence & 0.62 & 0.27 & 2.3 & 0.038 & - & - & - & - & - & - & - & - \\
\hline Cicatrix scar & 0.07 & 0.26 & 0.29 & 0.775 & - & - & - & - & - & - & - & - \\
\hline Pseudomembrane & 0.21 & 0.32 & 0.65 & 0.526 & - & - & - & - & - & - & - & - \\
\hline Malacia & -0.47 & 0.24 & -1.95 & 0.074 & -0.05 & 0.19 & -0.25 & 0.805 & - & - & - & - \\
\hline $\begin{array}{l}\text { \# of bronchoscopies/month } \\
\text { pre stent }\end{array}$ & -0.32 & 0.28 & -1.15 & 0.271 & - & - & - & - & - & - & - & - \\
\hline Days prior to stent placement & 0 & 0 & -2.61 & 0.022 & 0 & 0 & -1.81 & 0.108 & 0 & 0 & -3.07 & 0.01 \\
\hline \# of days with stent & 0 & 0 & -2.08 & 0.057 & 0 & 0 & 0.17 & 0.868 & - & - & - & - \\
\hline $\begin{array}{l}\text { \# of bronchoscopies/month } \\
\text { during stent }\end{array}$ & 0.31 & 0.06 & 4.83 & 0 & 0.25 & 0.07 & 3.83 & 0.005 & 0.27 & 0.05 & 5.23 & 0 \\
\hline \multicolumn{13}{|l|}{ Stent related complications } \\
\hline Mucous plugging & -0.28 & 0.25 & -1.12 & 0.282 & - & - & - & - & - & - & - & - \\
\hline Migration & -0.13 & 0.29 & -0.47 & 0.648 & - & - & - & - & - & - & - & - \\
\hline Bleeding & 0.24 & 0.51 & 0.46 & 0.65 & - & - & - & - & - & - & - & - \\
\hline Granulation tissue & -0.08 & 0.26 & -0.32 & 0.753 & - & - & - & - & - & - & - & - \\
\hline Fracture & - & - & - & - & - & - & - & - & - & - & - & - \\
\hline Restenosis & 0.05 & 0.29 & 0.16 & 0.876 & - & - & - & - & - & - & - & - \\
\hline Dehiscence & -0.06 & 0.51 & -0.12 & 0.905 & - & - & - & - & - & - & - & - \\
\hline $\begin{array}{l}\text { Symptomatic improvement after } \\
\text { stent }\end{array}$ & - & - & - & - & - & - & - & - & - & - & - & - \\
\hline \# of stent exchanges & 0.08 & 0.1 & 0.81 & 0.431 & - & - & - & - & - & - & - & - \\
\hline
\end{tabular}

FEV1, forced expiratory volume over 1 second; LMSB, left mainstem bronchus; RMSB, right mainstem bronchus; RBI, right bronchus intermedius; CSEMS, covered self expanding metallic stent; USEMS, uncovered self expanding metallic stent. 
Table S4 Predictors of changes in frequency of bronchoscopy after stent placement. $\mathrm{Y}=\Delta \mathrm{bronch} / \mathrm{month}(\mathrm{during}-\mathrm{pre}), \mathrm{n}=36$

\begin{tabular}{|c|c|c|c|c|c|c|c|c|c|c|c|c|}
\hline \multirow[b]{2}{*}{ Predictors } & \multicolumn{4}{|c|}{ Univariate } & \multicolumn{4}{|c|}{ Multivariate } & \multicolumn{4}{|c|}{ Reduced } \\
\hline & Estimate & $\begin{array}{l}\text { Standard } \\
\text { error }\end{array}$ & Chi-sq & $P$ value & Estimate & $\begin{array}{l}\text { Standard } \\
\text { error }\end{array}$ & $t$-value & $P$ value & Estimate & $\begin{array}{l}\text { Standard } \\
\text { error }\end{array}$ & $t$-value & $P$ value \\
\hline Age at transplant & -0.02 & 0.02 & -1.03 & 0.312 & - & - & - & - & - & - & - & - \\
\hline Gender & 0.51 & 0.33 & 1.53 & 0.135 & 0.82 & 0.33 & 2.51 & 0.017 & 0.78 & 0.33 & 2.33 & 0.026 \\
\hline Baseline FEV1 & -0.32 & 0.31 & -1.05 & 0.304 & - & - & - & - & - & - & - & - \\
\hline Location of stent & & & & 0.686 & - & - & - & - & - & - & - & - \\
\hline LMSB & -0.27 & 0.56 & -0.47 & 0.639 & - & - & - & - & - & - & - & - \\
\hline RMSB & -0.69 & 0.64 & -1.08 & 0.289 & - & - & - & - & - & - & - & - \\
\hline $\mathrm{RBI}$ & -0.17 & 0.66 & -0.25 & 0.803 & - & - & - & - & - & - & - & - \\
\hline Peripheral & REF & & & & - & - & - & - & - & - & - & - \\
\hline Type of stent & & & & 0.384 & - & - & - & - & - & - & - & - \\
\hline CSEMS & 0.44 & 0.54 & 0.81 & 0.425 & - & - & - & - & - & - & - & - \\
\hline USEMS & 0.52 & 0.41 & 1.28 & 0.21 & - & - & - & - & - & - & - & - \\
\hline Silicone & REF & & & & - & - & - & - & - & - & - & - \\
\hline \multicolumn{13}{|l|}{ Type of airway complication } \\
\hline Dehiscence & 0.74 & 0.47 & 1.57 & 0.126 & 1.04 & 0.46 & 2.27 & 0.03 & 1.11 & 0.47 & 2.36 & 0.024 \\
\hline Cicatrix scar & -0.05 & 0.34 & -0.14 & 0.89 & - & - & - & - & - & - & - & - \\
\hline Pseudomembrane & -0.25 & 0.39 & -0.66 & 0.515 & - & - & - & - & - & - & - & - \\
\hline Malacia & -0.4 & 0.34 & -1.19 & 0.241 & - & - & - & - & - & - & - & - \\
\hline Days prior to stent placement & 0 & 0 & -0.33 & 0.74 & - & - & - & - & - & - & - & - \\
\hline \# of days with stent & 0 & 0 & -1.59 & 0.121 & 0 & 0 & -1.71 & 0.096 & - & - & - & - \\
\hline \multicolumn{13}{|l|}{ Stent Related complications } \\
\hline Mucous plugging & -0.24 & 0.34 & -0.71 & 0.485 & - & - & - & - & - & - & - & - \\
\hline Migration & 0.2 & 0.36 & 0.54 & 0.593 & - & - & - & - & - & - & - & - \\
\hline Bleeding & -0.17 & 0.54 & -0.31 & 0.755 & - & - & - & - & - & - & - & - \\
\hline Granulation tissue & -0.15 & 0.35 & -0.44 & 0.664 & - & - & - & - & - & - & - & - \\
\hline Fracture & - & - & - & - & - & - & - & - & - & - & - & - \\
\hline Restenosis & 0.02 & 0.43 & 0.04 & 0.965 & - & - & - & - & - & - & - & - \\
\hline Dehiscence & -0.28 & 0.73 & -0.38 & 0.709 & - & - & - & - & - & - & - & - \\
\hline $\begin{array}{l}\text { Symptomatic improvement } \\
\text { after stent }\end{array}$ & 0.17 & 0.51 & 0.33 & 0.741 & - & - & - & - & - & - & - & - \\
\hline \# of stent exchanges & 0 & 0.12 & -0.01 & 0.992 & - & - & - & - & - & - & - & - \\
\hline
\end{tabular}

FEV1, forced expiratory volume over 1 second; LMSB, left mainstem bronchus; RMSB, right mainstem bronchus; RBI, right bronchus intermedius; CSEMS, covered self expanding metallic stent; USEMS, uncovered self expanding metallic stent. 
Table S5 Predictors of changes in frequency of bronchoscopy after stent removal. $\mathrm{Y}=\Delta$ bronch/month (after - pre), $\mathrm{n}=21$

\begin{tabular}{|c|c|c|c|c|c|c|c|c|c|c|c|c|}
\hline \multirow[b]{2}{*}{ Predictors } & \multicolumn{4}{|c|}{ Univariate } & \multicolumn{4}{|c|}{ Multivariate } & \multicolumn{4}{|c|}{ Reduced } \\
\hline & Estimate & $\begin{array}{l}\text { Standard } \\
\text { error }\end{array}$ & $t$-value & $P$ value & Estimate & $\begin{array}{l}\text { Standard } \\
\text { error }\end{array}$ & $t$-value & $P$ value & Estimate & $\begin{array}{l}\text { Standard } \\
\text { error }\end{array}$ & $t$-value & $P$ value \\
\hline Age at transplant & -0.01 & 0.01 & -0.66 & 0.514 & - & - & - & - & - & - & - & - \\
\hline Gender & 0.27 & 0.24 & 1.16 & 0.259 & - & - & - & - & - & - & - & - \\
\hline Baseline FEV1 & -0.3 & 0.16 & -1.91 & 0.073 & -0.38 & 0.2 & -1.88 & 0.083 & - & - & - & - \\
\hline Location of stent & & & & 0.891 & - & - & - & - & - & - & - & - \\
\hline LMSB & 0.23 & 0.34 & 0.69 & 0.498 & - & - & - & - & - & - & - & - \\
\hline RMSB & 0.09 & 0.39 & 0.22 & 0.827 & - & - & - & - & - & - & - & - \\
\hline RBI & 0.01 & 0.64 & 0.01 & 0.989 & - & - & - & - & - & - & - & - \\
\hline Peripheral & REF & & & & - & - & - & - & - & - & - & - \\
\hline Type of stent & & & & 0.981 & - & - & - & - & - & - & - & - \\
\hline CSEMS & -0.07 & 0.37 & -0.18 & 0.861 & - & - & - & - & - & - & - & - \\
\hline USEMS & 0.01 & 0.28 & 0.04 & 0.97 & - & - & - & - & - & - & - & - \\
\hline Silicone & REF & & & & - & - & - & - & - & - & - & - \\
\hline \multicolumn{13}{|l|}{ Type of airway complication } \\
\hline Dehiscence & 0.01 & 0.31 & 0.05 & 0.963 & - & - & - & - & - & - & - & - \\
\hline Cicatrix scar & -0.11 & 0.24 & -0.47 & 0.645 & - & - & - & - & - & - & - & - \\
\hline Pseudomembrane & -0.33 & 0.26 & -1.3 & 0.208 & - & - & - & - & - & - & - & - \\
\hline Malacia & 0.08 & 0.26 & 0.31 & 0.756 & - & - & - & - & - & - & - & - \\
\hline Days prior to stent placement & 0 & 0 & 0.97 & 0.344 & - & - & - & - & - & - & - & - \\
\hline \# of days with stent & 0 & 0 & -1.53 & 0.143 & 0 & 0 & -1.06 & 0.31 & - & - & - & - \\
\hline \multicolumn{13}{|l|}{ Stent related complications } \\
\hline Mucous plugging & -0.21 & 0.24 & -0.87 & 0.393 & - & - & - & - & - & - & - & - \\
\hline Migration & 0.21 & 0.28 & 0.75 & 0.462 & - & - & - & - & - & - & - & - \\
\hline Bleeding & -0.05 & 0.41 & -0.13 & 0.9 & - & - & - & - & - & - & - & - \\
\hline Granulation tissue & -0.34 & 0.23 & -1.45 & 0.164 & 0.02 & 0.25 & 0.09 & 0.931 & - & - & - & - \\
\hline Fracture & - & - & - & - & - & - & - & - & - & - & - & - \\
\hline Restenosis & -0.43 & 0.25 & -1.74 & 0.098 & 0 & 0.28 & 0 & 0.997 & - & - & - & - \\
\hline Dehiscence & -0.26 & 0.41 & -0.64 & 0.532 & - & - & - & - & - & - & - & - \\
\hline $\begin{array}{l}\text { Symptomatic improvement after } \\
\text { stent }\end{array}$ & -0.15 & 0.57 & -0.27 & 0.794 & - & - & - & - & - & - & - & - \\
\hline \# of stent exchanges & -0.19 & 0.08 & -2.34 & 0.03 & -0.08 & 0.09 & -0.85 & 0.409 & -0.19 & 0.08 & -2.34 & 0.03 \\
\hline
\end{tabular}

FEV1, forced expiratory volume over 1 second; LMSB, left mainstem bronchus; RMSB, right mainstem bronchus; RBI, right bronchus intermedius; CSEMS, covered self expanding metallic stent; USEMS, uncovered self expanding metallic stent. 